\title{
Predictors and clinical features of methotrexate (MTX) therapy for ectopic pregnancy
}

\author{
Jing Zhang, Yu Zhang, Lu Gan, Xiao-ying Liu and Shan-ping Du*
}

\begin{abstract}
Background: Ectopic pregnancy is a major life- and fertility-threatening women's health concern. As a result of advances in examination technology, an increasing number of ectopic pregnancies can be diagnosed early and treated with medical methods instead of surgery. The aim of this study was to summarize the clinical features and identify the predictors of success of methotrexate (MTX) treatment of ectopic pregnancy.

Methods: This was a retrospective study of 238 ectopic pregnancies treated with MTX in the Department of Gynecology of Shaanxi Provincial People's Hospital from January 2017 to December 2017.

Results: Patients were divided into two groups: the successful treatment group $(n=166)$ and the failed treatment group $(n=72)$. The overall success rate of MTX therapy for ectopic pregnancy was $69.75 \%$. The mean initial betahuman chorionic gonadotropin ( $\beta$-hCG) level was significantly lower in the successful treatment group than in the failed treatment group $(2538.08 \mathrm{IU} / \mathrm{L}$ versus $3533.17 \mathrm{IU} / \mathrm{L}, P=0.000$ ). The treatment success rate of the group with an initial $\beta$-hCG concentration less than $4000 \mathrm{IU} / \mathrm{L}$ was significantly higher than that of the group with an initial $\beta$-hCG concentration greater than $4000 \mathrm{IU} / \mathrm{L}$. However, the success rate of the group with an initial $\beta$-hCG concentration greater than $4000 \mathrm{IU} / \mathrm{L}$ was still relatively high (54.55\%). $\beta$-hCG levels were significantly increased on the 4 th day in the failed treatment group $(P=0.000)$. Compared to the initial $\beta$-hCG level, the day- $4 \beta$-hCG level increased by more than $8.21 \%$, indicating that the treatment was effective. The diagnostic sensitivity was $88.6 \%$, the specificity was $74.5 \%$, and the area under the receiver operating characteristic (ROC) curve was 0.863 (95\% confidence interval (Cl): 0.805-0.920).
\end{abstract}

Conclusions: MTX therapy as a treatment option is safe and effective for asymptomatic, hemodynamically stable patients with ectopic pregnancies who are interested in conservative treatment, regardless of the serum $\beta$-hCG level or adnexal mass size. The change in the $\beta$-hCG level between the initial day and the 4th day is an effective and early predictive tool for the success of MTX therapy for ectopic pregnancy.

Keywords: Ectopic pregnancy, MTX therapy, $\beta$-hCG 


\section{Background}

Ectopic pregnancy is a common acute abdominal disease in obstetrics and gynecology with a reported incidence of approximately $2 \%$ and is a common cause of maternal death, accounting for $10 \%$ of maternal deaths. In recent years, its incidence has increased due to the increase in the prevalence of pelvic inflammatory diseases and the increased use of assisted reproductive technologies [1-3]. Although traditional salpingectomy is a reliable treatment approach, it involves the loss of the fallopian tubes and the risks inherent in undergoing surgery. With improvements in diagnostic technology, most ectopic pregnancies can be identified early and treated with conservative methods [1]. Medical management not only retains the fallopian tubes but also avoids the risk of pain and high costs associated with surgery. Methotrexate (MTX) has been validated and is widely used for the conservative treatment of ectopic pregnancy. However, the protocol suggests that initial beta-human chorionic gonadotropin ( $\beta$-hCG) level and the size of the adnexal mass should be below certain cutoff values; for example, in China, this treatment is recommended for hemodynamically stable patients with initial $\beta$-hCG levels less than $2000 \mathrm{IU} / \mathrm{L}$ and the adnexal mass less than $4 \mathrm{~cm}$ in diameter. However, the question of whether some hemodynamically stable patients who wish to avoid surgery and do not meet the above criteria can avoid surgery by undergoing conservative treatment remains unanswered. The follow-up of patients treated with MTX requires the assessment of $\beta$ hCG levels on days 0,4 , and 7 after MTX is administered at a dose of $50 \mathrm{mg} / \mathrm{m}^{2}$. A $15 \%$ decrease in the $\beta$-hCG level from day 4 to day 7 is defined as a factor indicating initial success that can be used as a basis for follow-up treatment decisions. However, patients treated with this protocol have to experience anxiety while waiting seven days to obtain an assessment of the effectiveness of treatment. It is important to predict the outcome of this treatment earlier so that we can provide patient recommendations such as surgery or the continuation of follow-up. The $\beta$-hCG level on day 4 during the course of treatment might give us some indication of the success of the treatment. These questions remain unanswered. The aim of this study was to investigate the factors predictive of therapeutic success and related factors influencing the success rate of conservative treatment.

\section{Materials and methods}

\section{General data collection}

We conducted a retrospective cohort study of 238 patients with tubal ectopic pregnancies who requested conservative medical treatment in the Department of Gynecology of the Shaanxi Provincial People's Hospital from January 2017 to December 2017. Ectopic pregnancy was diagnosed by means of a standard set of criteria based on clinical and sonological parameters and serial $\beta$-hCG values, including the occurrence of persistent/rising $\beta$-hCG values without intrauterine evidence of pregnancy on sonography or histological examination and an adnexal mass or extrauterine gestational sac on sonography. All eligible women who consented to receive MTX treatment for ectopic pregnancy were included. The inclusion criteria were as follows: the patient had an unruptured tubal ectopic pregnancy; the patient had no embryonic cardiac activity;the patient desired to retain her future fertility or had refused surgery (especially if the $\beta$-hCG level was $<2000 \mathrm{IU} / \mathrm{L}$ or if the adnexal mass was $4 \mathrm{~cm}$ or less); and the patient had no contraindications for MTX therapy. The presence of minimal free fluid in the pouch of Douglas was not a contraindication for MTX therapy as long as the patient was hemodynamically stable. Women who strongly desired to retain their reproductive function could receive conservative medical treatment on the basis of informed consent regardless of the initial $\beta$-hCG level and the size of the adnexal mass.

The exclusion criteria were acute ruptured ectopic pregnancy, nontubal ectopic pregnancy, conservative treatment drug contraindications and loss to follow-up. Successful treatment was defined as a $\beta$-hCG level that was normalized, an adnexal mass that was reduced or that had disappeared on B-mode ultrasound, and symptoms of abdominal discomfort that had eased without surgical intervention. All patients received a single intramuscular injection of MTX calculated to deliver a dose of $50 \mathrm{mg} /$ $\mathrm{m}^{2}$. Follow-up assessments were conducted once a week until a cure was achieved. Follow-up included assessments of the patient's general physical condition and abdominal symptoms; monitoring of chemotherapy side effects; blood $\beta$-hCG measurements and ultrasound examinations if necessary to check whether the embryo sac had disappeared; assessments to determine whether pelvic free fluid was reduced; and assessments to determine whether the ectopic pregnancy lesions were reduced.

The $\beta$-hCG levels were measured on the initial day, the 4th day and the 7th day after MTX was administered. The clinical outcome was analyzed based on the complete resolution of $\beta$-hCG levels, the need for additional doses of MTX or recourse to surgery. If the decrease in the $\beta$-hCG level of MTX on the 7th day was less than $15 \%$ of that on the 4 th day, the patient was switched to surgery or given a second injection of MTX according to the patient's general situation. The percentage change in the $\beta$-hCG level (the $\beta$-hCG index) between the initial day and the 4th day was calculated for each case and was defined as the difference in the $\beta$ hCG level between the initial day and the 4th day divided by the day- 0 value and multiplied by 100 (HCG4-HCG0/HCG0*100). 


\section{Treatment flow chart}

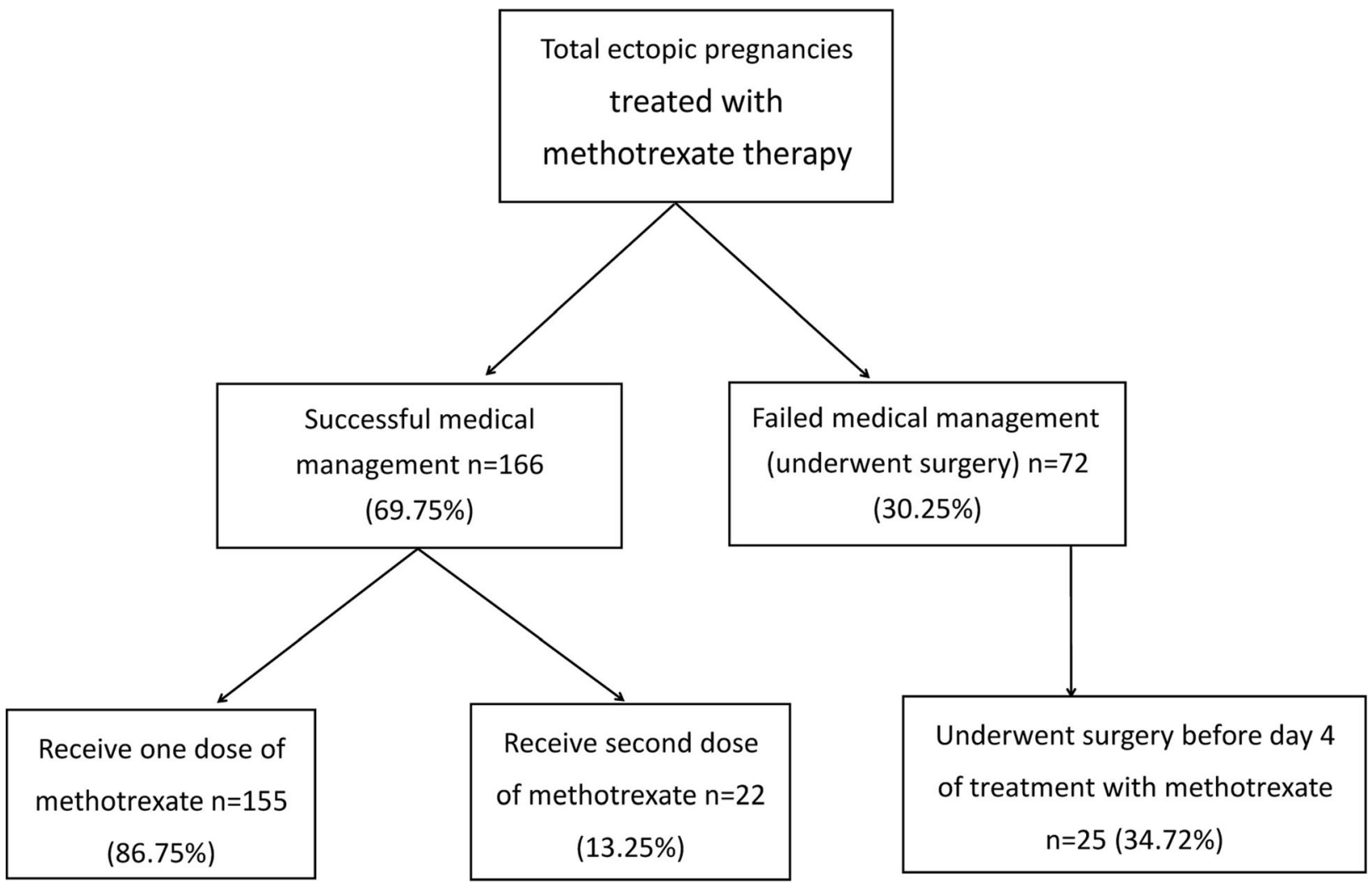

Fig. 1 Participants selection flowchart and the number of participants among subgroups of the study population

\section{Statistical methods}

The data were analyzed using the Statistical Product and Service Solutions (SPSS) Statistical Package, Version 23.0 (Chicago, Illinois). General data, including age, weight, height, and other normally distributed data, were analyzed using a Student's t test. The measurement data (including the $\beta$-hCG index and $\beta$-hCG change trend) were not normally distributed, so the Mann-Whitney $U$ test and the rank-sum test were adopted. Discrete and categorical variables were analyzed with frequency distributions.
Screening for extreme values among quantitative variables was performed using Box-Cox plots and histograms. The best cutoff value for the $\beta$-hCG index between the initial day and the 4th day was obtained using the receiver operator characteristic (ROC) curve method.

\section{Results}

\section{Baseline data}

A total of 238 women with ectopic pregnancies were treated with MTX therapy. The maximum age of the patients was

Table 1 Patient characteristics

\begin{tabular}{llll}
\hline Variable & Successful $(\boldsymbol{n = 1 6 6 )}$ & Failed $(\boldsymbol{n}=\mathbf{7 2})$ & $\boldsymbol{P}$ value \\
\hline Age (years) & $29.05 \pm 4.80$ & $29.85 \pm 5.85$ & $0.258^{\mathrm{a}}$ \\
Amenorrhea (days) & $47.18 \pm 6.79$ & $47.28 \pm 6.36$ & $0.833^{\mathrm{a}}$ \\
Parity & $1.86 \pm 0.96$ & $1.69 \pm 1.17$ & $0.510^{\mathrm{c}}$ \\
First pregnancy $\mathrm{n}(\%)$ & $38(22.89 \%)$ & $15(20.83 \%)$ & $0.726^{\mathrm{b}}$ \\
Body surface area (m $\left.{ }^{2}\right)$ & $1.55 \pm 0.10$ & $1.54 \pm 0.10$ & $0.587^{c}$ \\
Longest ectopic mass diameter (mm) & $2.98 \pm 1.25$ & $2.99 \pm 1.05$ & $0.932^{\mathrm{a}}$ \\
Initial $\beta$-hCG level (IU/L) & $2538.08 \pm 3107.07$ & $3533.17 \pm 1967.80$ & $0.000^{\mathrm{c}}$
\end{tabular}

(a, mean \pm SD and Student's t-test. b, chi-squared test. c, mean \pm SD and Mann-Whitney $U$ test) 
Table $2 \beta$-hCG changes

\begin{tabular}{lllll}
\hline Variable & Successful $(\boldsymbol{n}=\mathbf{1 6 6})$ & Failed $(\boldsymbol{n}=\mathbf{7 2})$ & $\mathbf{Z}$ & $\mathbf{P}$ \\
\hline $\mathrm{HCG}_{0}$ & $2538.08 \pm 3107.07$ & $3533.17 \pm 1967.80$ & -4.780 & 0.000 \\
$\mathrm{HCG}_{4}$ & $1975.83 \pm 3443.05$ & $4549.87 \pm 3379.32$ & -6.182 & 0.000 \\
$\mathrm{HCG}_{7}$ & $1505.50 \pm 2044.40$ & $3407.18 \pm 3610.90$ & -3.513 & 0.000 \\
$\mathrm{HCG}_{0-4}$ & $-0.30 \pm 0.48$ & $0.53 \pm 0.73$ & -7.584 & 0.000 \\
$\mathrm{HCG}_{4-7}$ & $-0.35 \pm 0.31$ & $-0.05 \pm 0.32$ & -0.3981 & 0.000 \\
\hline
\end{tabular}

44 years, and the minimum age was 15 years. After MTX treatment, all patients were divided into two groups according to the final treatment outcome: there were 166 patients in the successful treatment group and 72 patients who switched from MTX treatment to surgery in the failed treatment group (25 women underwent surgery before day 4 of MTX). Some patients were treated with antimicrobial drugs if necessary, such as if they presented with fever and an elevated white blood cell count (36 patients in the successful treatment group and 11 patients in the failed treatment group, with no statistically significant difference between the two groups). The follow-up duration was 1-6 months.

The overall success rate of MTX therapy was $69.75 \%$ (166/ 238), and 22 patients (13.25\%) required a second dose of MTX to achieve complete resolution. There were 72 patients in whom treatment failed $(30.25 \%, 72 / 238)$ (Fig. 1). The baseline data for the successful and failed treatment groups are shown in Table 1 . There were no statistically significant differences in the demographic profiles of the groups (Table 1).

\section{Relationship between $\beta$-hCG changes and treatment outcomes}

The mean $\beta$-hCG levels on day 0 , day 4 and day 7 in the successful treatment group and failed treatment group are shown in Table 2. The rank-sum test showed statistically significant differences between the two groups $(P<$ 0.001). In total, $92.47 \%(135 / 146)$ of the patients in whom $\beta$-hCG levels were decreased on the 4 th day were in the successful treatment group. In contrast, in the

\section{ROC curve of the initial level \\ ROC Curve}

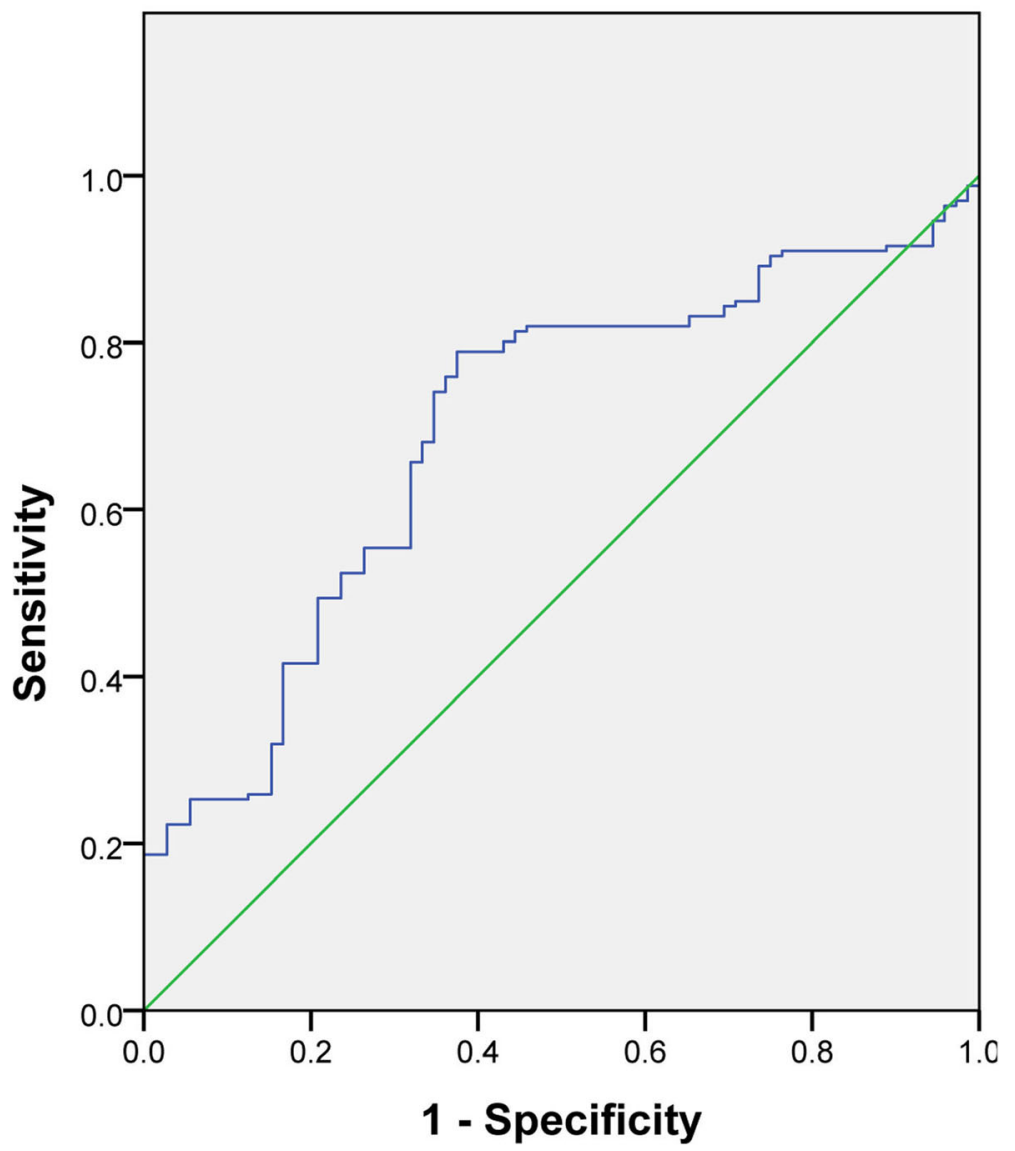

Fig. 2 The ROC curves used to evaluate the predictive efficiencies of initial $\beta$-hCG level to MTX therapy for ectopic pregnancy. The area under ROC curve was 0.695 (95\% Cl: 0.624-0.767) 
group of patients in whom the day-4 $\beta$-hCG levels had increased, only $56.27 \%(31 / 67)$ were successfully treated with MTX ( $P$ value $=0.000$, chi-squared test).

The changes in $\beta$-hCG levels $\left(\mathrm{hCG}_{04}\right)$ between the initial day and the 4th day were calculated as $\left(\mathrm{HCG}_{4}{ }^{-}\right.$ $\left.\mathrm{HCG}_{0}\right) / \mathrm{HCG}_{0}$. The changes in $\beta$-hCG levels $\left(\mathrm{hCG}_{4-7}\right)$ between the 4th day and the 7th day were calculated as $\left(\mathrm{HCG}_{7}-\mathrm{HCG}_{4}\right) / \mathrm{HCG}_{4}$. Negative numbers indicate that the $\beta$-hCG levels decreased, and positive numbers indicate that the levels increased (Table 2).

\section{The initial $\beta$-hCG level and changes in the $\beta$-hCG levels between the initial day and day 4 and between day 4 and day 7 predict the outcome of treatment}

The areas under the ROC curves (Figs. 2, 3 and 4) for the initial $\beta$-hCG level, the change in the level from day 0 to 4 and the change in the level from day 4 to day 7 were 0.695 (95\% CI: 0.624-0.767), 0.863 (95\% CI: 0.8050.920 ) and 0.767 (95\% CI: 0.685-0.877), respectively. The diagnostic value of the change from day 0 to day 4 was higher than that of the other two. The best cutoff value for the initial $\beta$-hCG level was $3393.78 \mathrm{IU} / \mathrm{L}$, which provided a sensitivity of $78.9 \%$ and a specificity of $62.5 \%$. The positive predictive value was $67.78 \%$, and the negative predictive value was $74.76 \%$. The best cutoff value for the change in the $\beta$-hCG level from day 0 to day 4 was $0.082(8.2 \%)$. This cutoff value provided a sensitivity of $88.6 \%$ and a specificity of $74.5 \%$. The positive predictive value was $77.65 \%$, and the negative predictive value was $86.73 \%$. The best cutoff value for the change in the $\beta$ hCG level from day 4 to day 7 was $-0.139(-13.9 \%)$. This cutoff value provided a sensitivity of $85 \%$ and a specificity of $63.6 \%$. The positive predictive value was $70.02 \%$, and the negative predictive value was $80.92 \%$. The various cutoff values for the initial $\beta$-hCG level, the change in the level from day 0 to day 4 and the change in the level from day 4 to day 7 are depicted in Tables 3,4 and 5, respectively.

The chi-squared test was used to analyze the difference between the treatment success rate of the group with an initial $\beta$-hCG concentration greater than 4000 IU/L and that of the group with an initial $\beta$-hCG concentration less than $4000 \mathrm{IU} / \mathrm{L}(P=0.005<0.05)$, and the test indicated a significant difference. However, the

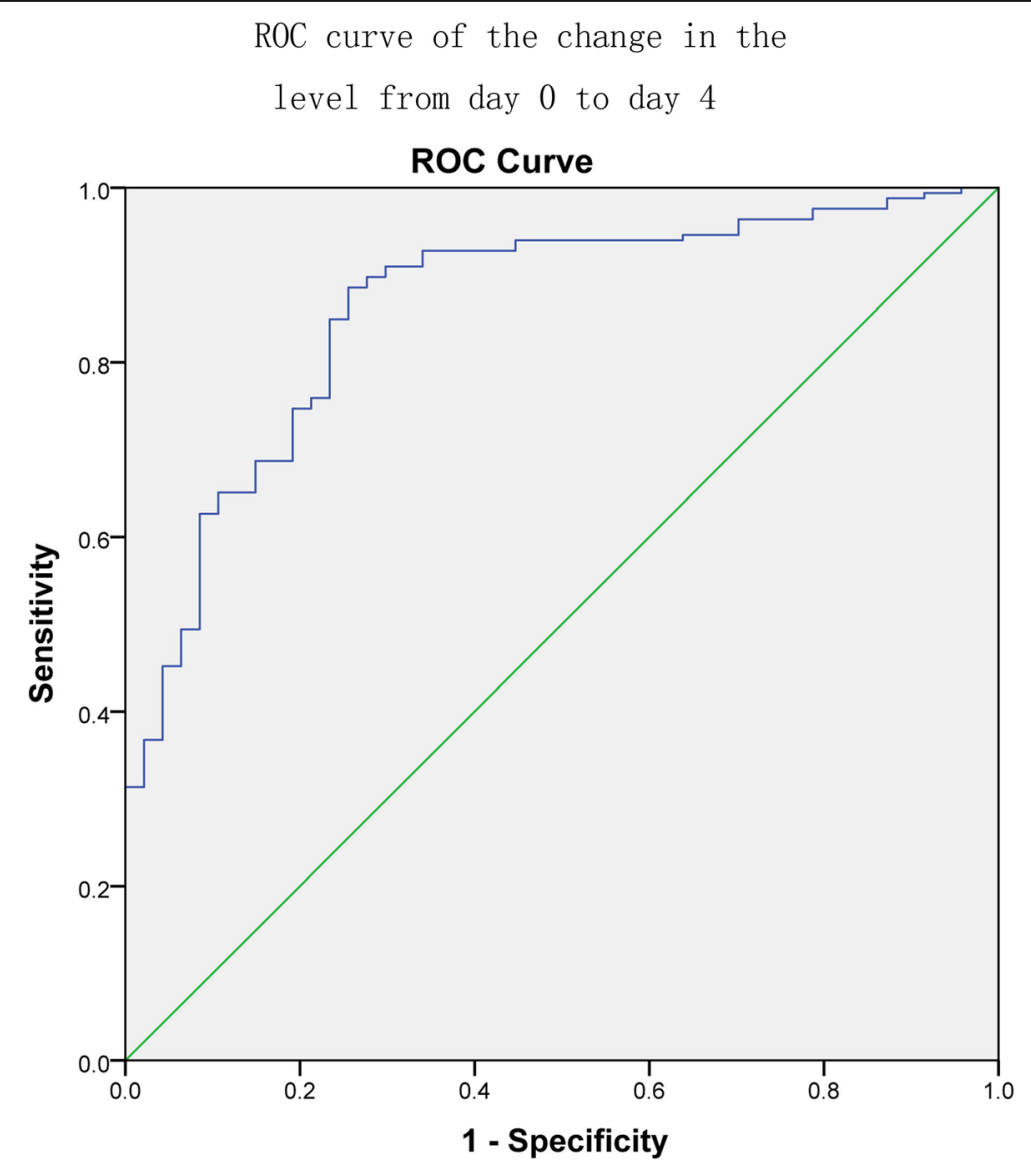

Fig. 3 The ROC curves used to evaluate the predictive efficiencies of the change in the level from day 0 to day 4 to MTX therapy for ectopic pregnancy. The area under ROC curve was 0.863 (95\% Cl: 0.805-0.920) 


\section{ROC curve of the change in the level from day 4 to day 7}

ROC Curve

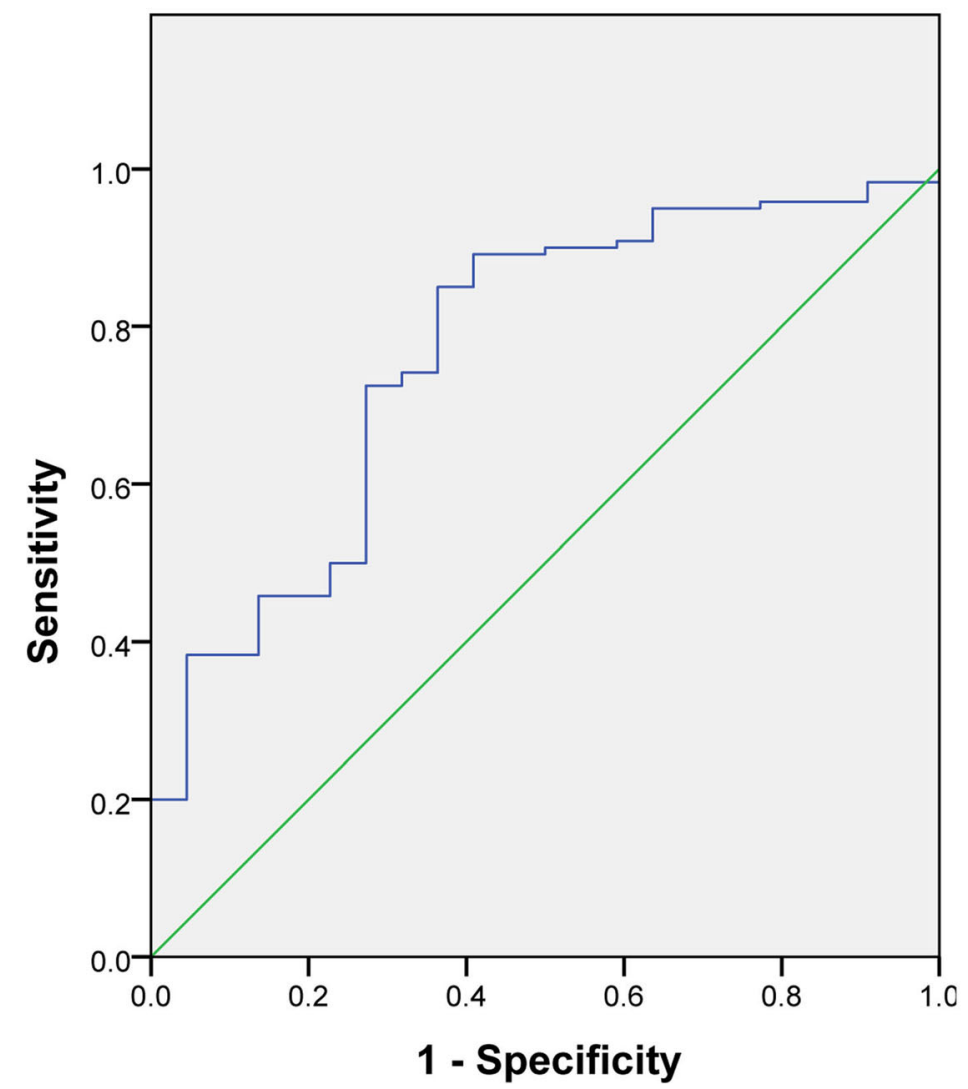

Fig. 4 The ROC curves used to evaluate the predictive efficiencies of the change in the level from day 4 to day 7 to MTX therapy for ectopic pregnancy. The area under ROC curve was 0.767 (95\% Cl: 0.685-0.877)

success rate for the group with an initial $\beta$-hCG concentration greater than $4000 \mathrm{IU} / \mathrm{L}$ was still more than $50 \%$ (54.55\%, Table 6).

\section{Side effects}

Of the 238 patients, 11 patients (4.62\%) experienced nausea and vomiting after receiving the medication (similar to after receiving $10 \mathrm{mg}$ of metoclopramide via intramuscular injection), which resolved without intervention, and 5 patients $(2.10 \%)$ showed slight increases in transaminase levels, which normalized after hepatoprotective drug treatment $(456 \mathrm{mg}$ polyene phosphatidylcholine capsules 3 times/day with liver function evaluated every week until it returned to normal); however, the other patients had no obvious adverse reactions.

\section{Discussion}

MTX treatment is safe and effective. According to the statistics in the literature, the success rate of MTX treatment varies from 65 to $95 \%$, with a mean rate of $82 \%$, and the fertility rate with delivery after medical treatment for ectopic pregnancy is $67-80.7 \%$, which is not less than that after conservative and radical surgery [4-7], [8-12]. Meanwhile, MTX does not damage ovarian function or increase the incidence of subsequent adverse pregnancy and birth outcomes in patients [13-15]. An increasing number of patients with unruptured ectopic pregnancies are seeking MTX treatment [16]; however, it is unknown which patients will benefit the most from it. Many studies have tried to identify the factors that influence the success rate before starting treatment with MTX, such as the initial $\beta$-hCG concentration, the size of the ectopic mass and a history of previous ectopic pregnancy [17]. Most studies found that only the initial $\beta$-hCG level might be a predictor of successful MTX therapy in patients with ectopic pregnancy $[8,9,18,19]$. The present results were consistent with those of previous studies. The success rate of the group with an initial $\beta$-hCG concentration less than 4000 
Table 3 Performance of various cut-off levels of $\mathrm{HCG}_{0}$

\begin{tabular}{lll}
\hline Positive if less than or equal to & Sensitivity & $\mathbf{1}$-Specificity \\
\hline 668.125 & 0.187 & 0 \\
723.775 & 0.223 & 0.028 \\
758.17 & 0.253 & 0.056 \\
806.55 & 0.259 & 0.125 \\
962.28 & 0.319 & 0.153 \\
1183.585 & 0.416 & 0.167 \\
1540.615 & 0.494 & 0.208 \\
1801.775 & 0.524 & 0.236 \\
1896.08 & 0.554 & 0.292 \\
2339.585 & 0.657 & 0.319 \\
2679.335 & 0.681 & 0.333 \\
3166.525 & 0.741 & 0.347 \\
3297.475 & 0.759 & 0.361 \\
3393.775 & 0.789 & 0.375 \\
3689 & 0.801 & 0.431 \\
3855.89 & 0.813 & 0.444 \\
3907.83 & 0.819 & 0.458 \\
4342.15 & 0.831 & 0.653 \\
4369.375 & 0.843 & 0.694 \\
4389.52 & 0.849 & 0.708 \\
4744.325 & 0.892 & 0.736 \\
4808.21 & 0.904 & 0.75 \\
5148.365 & 0.91 & 0.764 \\
5618.305 & 0.916 & 0.889 \\
6706.185 & 0.946 & 0.944 \\
7408.48 & 0.964 & 0.958 \\
8276.08 & & 0.972 \\
9105.11 & & \\
$24,610.9$ & 0.986 \\
\hline & & \\
\hline
\end{tabular}

IU/L was significantly higher than that of the group with an initial $\beta$-hCG concentration greater than $4000 \mathrm{IU} / \mathrm{L}$. The size of the ectopic mass and a history of previous ectopic pregnancy were independent of the success rate. In contrast, Natale A et al. found no significant difference in initial $\beta$-hCG levels between the successful and unsuccessful treatment groups [8]. A retrospective analysis of ectopic pregnancy over a 10-year period published by Alison Richardson found that even when the initial $\beta$-hCG level was greater than $3000 \mathrm{IU} / \mathrm{L}$, medical management was still safe and successful, as $85.3 \%$ of women in this subgroup avoided surgery [8]. Our results also suggested that the success rate of the group with an initial $\beta$-hCG concentration greater than $4000 \mathrm{IU} / \mathrm{L}$ was still higher than $50 \%$. Thus, MTX should be more readily considered as a viable treatment option for asymptomatic, hemodynamically stable women with ectopic pregnancies regardless of their
Table 4 Performance of various cut-off levels of percentage changes in $\beta$-hCG from days 0 to 4 of methotrexate

\begin{tabular}{|c|c|c|}
\hline Positive if less than or equal to & Sensitivity & 1-Specificity \\
\hline-1.980036 & .000 & .000 \\
\hline-.570668 & .313 & .000 \\
\hline-.491563 & .367 & .021 \\
\hline-.381242 & .452 & .043 \\
\hline-.331703 & .494 & .064 \\
\hline-.213355 & .627 & .085 \\
\hline-.181529 & .651 & .106 \\
\hline-.137062 & .687 & .149 \\
\hline-.084988 & .747 & .191 \\
\hline-.057457 & .759 & .213 \\
\hline .032176 & .849 & .234 \\
\hline .082122 & .886 & .255 \\
\hline .155522 & .898 & .277 \\
\hline .188001 & .910 & .298 \\
\hline .246691 & .928 & .340 \\
\hline .355521 & .940 & .447 \\
\hline .553166 & .946 & .638 \\
\hline .859267 & .964 & .702 \\
\hline 1.027128 & .976 & .787 \\
\hline 1.261856 & .988 & .872 \\
\hline 1.704043 & .994 & .915 \\
\hline 2.331332 & 1.000 & .957 \\
\hline 3.600508 & 1.000 & 1.000 \\
\hline
\end{tabular}

Table 5 Performance of various cut-off levels of percentage changes in $\beta$-hCG from days 4 to 7 of methotrexate

\begin{tabular}{lll}
\hline Positive if less than or equal to & Sensitivity & 1-Specificity \\
\hline-0.6 & 0.2 & 0 \\
-0.422 & 0.383 & 0.045 \\
-0.374 & 0.458 & 0.136 \\
-0.35 & 0.5 & 0.227 \\
-0.247 & 0.725 & 0.273 \\
-0.23 & 0.742 & 0.318 \\
-0.139 & $\mathbf{0 . 8 5}$ & $\mathbf{0 . 3 6 4}$ \\
-0.095 & 0.892 & 0.409 \\
-0.071 & 0.9 & 0.5 \\
-0.034 & 0.908 & 0.591 \\
0.121 & 0.95 & 0.636 \\
0.223 & 0.958 & 0.773 \\
0.476 & 0.983 & 0.909 \\
1.989 & 1 & 1 \\
\hline
\end{tabular}


Table 6 The outcomes of initial $\beta$-hCG ranges

\begin{tabular}{llll}
\hline hCG & Number of patients & Successful $(\boldsymbol{n}=\mathbf{1 6 6})$ & Failed $(\boldsymbol{n}=\mathbf{7 2})$ \\
\hline$\leq 4000$ & 183 & $74.32 \%(136)$ & $25.68 \%(47)$ \\
$>4000$ & 55 & $54.55 \%(30)$ & $45.45 \%(25)$ \\
\hline
\end{tabular}

initial serum $\beta$-hCG levels or adnexal mass sizes, however, they need a longer follow-up duration for repeated doses of MTX and have an increased incidence of emergency surgical intervention.

Although MTX treatment is an effective and safe option for stable patients with ectopic pregnancy, when the traditional diagnostic criterion, a > 15\% decrease in hCG between days 4 and 7 after administration, is used, prognostic information can be obtained only on day 7 of treatment. This disadvantage increases patient anxiety and the use of hospital resources and reduces treatment compliance and selectivity. Early predictors have long been a topic of concern among investigators. Obtaining early indicators of successful treatment may reduce the economic burden and psychological stress imposed on the patients, which has the potential to improve patient compliance. The literature reports that there is a transient increase in the $\beta$-hCG concentration in $26-60 \%$ of women who receive MTX therapy due to the effect of MTX on trophoblast cells [8-12]. This study also found that $28.16 \%$ of patients had higher $\beta$-hCG levels on the 4th day after MTX treatment, and the mean $\beta$-hCG level in the failed treatment group was significantly higher on the 4th day than on the initial day. Many previous studies have shown that changes in the serum $\beta$-hCG levels from day 0 to day 4 can provide an earlier indication of MTX treatment success for ectopic pregnancies. Agostini et al. [20] found that a cutoff level of a 20\% decrease in HCG levels between days 1 and 4 predicted the success rate with $97 \%$ sensitivity. Ustunyurt et al. [11] and Levin Gabriel et al. [21] proposed that $\mathrm{a}>22 \%$ decrease in $\beta$-hCG levels between days 1 and 4 is the best predictor of the treatment success of a single-dose regimen. Girija S. et al. [22] reported a cutoff value of a 10\% decrease in $\beta$-hCG levels between days 1 and 4 to predict the treatment success rate with a sensitivity of $77 \%$ and a specificity of $81 \%$. Lo Wong et al [23] suggested that a $6 \%$ drop in serum $\beta$-hCG from day 0 to day 4 was the best predictor of treatment success, with a positive predictive value of $91 \%$, which was not inferior to the traditional criterion from day 4 to day 7 . In our study, $92.47 \%$ of women with a decrease in the serum level of $\beta$-hCG from day 0 to day 4 were successfully treated without requiring surgical intervention. Furthermore, based on the ROC curve, a decrease in the $\beta$-hCG level of at least $8.2 \%$ between the initial day and the 4th day was associated with an $88.6 \%$ probability of therapeutic success without further intervention, which was higher than the current criterion of a $15 \%$ decrease in the $\beta$ hCG level from day 4 to day 7 (76.7\%) and the initial $\beta$-hCG level (69.5\%) to predict treatment success. In addition, in all the previous studies mentioned above, treatment success was defined based on a single dose of MTX, and patients who received two or more doses and/or surgery were classified in the failed treatment group. To the best of our knowledge, the present study is the first trial to classify all patients who did not need surgery in the successful treatment group, including those who received two or more doses of MTX. The common adverse reactions to MTX treatment for ectopic pregnancies, such as stomatitis and nausea, are usually mild and selflimiting. In our study, the incidence of adverse reactions in patients receiving treatment with MTX was only $5.16 \%$, and all of the side effects were mild and reversible, even when the patients received two or more injections.

\section{Conclusion}

In conclusion, MTX therapy for ectopic pregnancy is a safe, effective and superior choice for women with ectopic pregnancies who are asymptomatic and hemodynamically stable regardless of their initial serum $\beta$-hCG levels or adnexal mass sizes. The change in the $\beta$-hCG level between day 0 and day 4 is a good predictor of the treatment outcome.

\section{Abbreviations}

MTX: Methotrexate; $\beta$-hCG: Beta-human chorionic gonadotropin; ROC: Receiver operator characteristic

\section{Acknowledgments}

Not applicable.

\section{Authors' contributions}

S.P.D. and J.Z. contributed to the conception of the study. J.Z. and Y. Z. contributed significantly to the analysis and manuscript preparation. J.Z. and L.G. performed the data analyses and wrote the manuscript. X.Y.L. helped perform the analysis and participated in constructive discussions. All authors have read and approved the manuscript.

\section{Funding}

This study was funded by Grants of the National Natural Science Foundation of China (Funding organization: the National Natural Science, P.R. China, grant number 81801414 , the recipient Lu Gan is the third author of the paper) and Key Research and Development Program of Shaanxi Province (Funding organization: the Health Department of Shaanxi Province, P.R. China, grant number 2018SF-253, and the recipient Jing Zhang is the first author of the paper). These funding bodies had no influence on the design of the study, the collection, analysis, and interpretation of data and in writing the manuscript.

Availability of data and materials

Data are available upon request due to ethical restrictions. Interested researchers may submit requests to Mrs. Jing Zhang for access to sensitive data. Contact: Shaanxi Provincial People's Hospital, Shaanxi Xian 710068,

China. E-mail: jingice24@163.com 


\section{Ethics approval and consent to participate}

The study was approved by the Ethics Committee of Shaanxi Provincial People's Hospital. All procedures were in accordance with the ethical standards of the National Research Committee and with the 1964 Helsinki declaration and its later amendments. All participants provided written informed consent.

\section{Consent for publication}

Not applicable.

\section{Competing interests}

The authors declare that they have no competing interests.

Received: 17 January 2020 Accepted: 20 October 2020

Published online: 29 October 2020

\section{References}

1. Committee on Practice Bulletins-Gynecology. ACOG Practice Bulletin No. 191 summary: tubal ectopic pregnancy. Obstet Gynecol. 2018;131(2):409-11. PMID:29370045. https://doi.org/10.1097/AOG.0000000000002499.

2. Chandrasekhar C. Ectopic pregnancy: A pictorial review. Clin Imag. 2008;32 468-73. PMID:19006776. https://doi.org/10.1016/j.clinimag.2008.02.027.

3. Brady PC. New evidence to guide ectopic pregnancy diagnosis and management. Obstet Gynecol Surv. 2017;72(10):618-25. PMID:29059454. https://doi.org/10.1097/OGX.0000000000000492.

4. Fernandez $\mathrm{H}$, Capmas P, Lucot JP, Jean RBPPB, et al. Fertility after ectopic pregnancy: the DEMETER randomized trial. Hum Reprod. 2013;28(5):124753. PMID:23482340. https://doi.org/10.1093/humrep/det037.

5. De Bennetot M, Rabischong B, Aublet-Cuvelier B, Belard F, Fernandez H, Bouyer J, et al. Fertility after tubal ectopic pregnancy: results of a population-based study. Fertil Steril. 2012;98(5):1271-6. PMID:22818285. https://doi.org/10.1016/j.fertnstert.2012.06.041.

6. Marreta H, Fauconnierc A, Dubernarde G, Misme H, Lagarce L, Lesavre M, et al. Overview and guidelines of off-label use of methotrexate in ectopic pregnancy: report by CNGOF [J]. Eur J Obstet Gynecol Reprod Biol. 2016; 205:105-9. PMID:27572300. https://doi.org/10.1016/j.ejogrb.2016.07.489.

7. Bonin L, Pedreiro C, Moret S, Chene G, Gaucherand P, Lamblin G. Predictive factors for the methotrexate treatment outcome in ectopic pregnancy: a comparative study of 400 cases [J]. Eur J Obstet Gynecol Reprod Biol. 2016; 208:23-30. PMID:27888702. https://doi.org/10.1016/j.ejogrb.2016.11.016.

8. Natale A, Busacca M, Candiani M, Gruft L, Izzo S, Felicetta I, et al. Human chorionic gonadotropin patterns after a single dose of methotrexate for ectopic pregnancy. Eur J Obstet Gynecol Reprod Biol. 2002;100(2):227-30. PMID:11750970. https://doi.org/10.1016/s0301-2115(01)00480-8.

9. Richardson A. Medical management of ectopic pregnancy: a 10-year case series [J]. Human Fertility (Camb). 2012;15(3):116-20. PMID:22591270. https:// doi.org/10.3109/14647273.2012.694571.

10. Nguyen Q, Kapitz M, Downes K, Silva C. Are early human chorionic gonadotropin levels after methotrexate therapy a predictor of response in ectopic pregnancy? Am J Obstet Gynecol. 2010;202(630):e1-5. PMID: 20510964. https://doi.org/10.1016/j.ajog.2010.03.022.

11. Ustunyurt E, Duran M, Coskun E, Ustunyurt $O B$, Simsek $H$. Role of initial and day 4 human chorionic gonadotropin levels in predicting the outcome of single-dose methotrexate treatment in women with tubal ectopic pregnancy. Arch Gynecol Obstet. 2013;288:1149-52. PMID:23666603. https:// doi.org/10.1007/s00404-013-2879-8.

12. Mirbolou F, Yousefnezhad A, Ghanbari A. Predicting factors of medical treatment success with single dose methotrexate in tubal ectopic pregnancy: a retrospective study. Iran J Reprod Med. 2015;13:351-4 PMID: 26330849. PMCID:PMC4555054.

13. Ohannessian A, Loundou A, Courbière B, Cravello L, Agostini A. Ovarian responsiveness in women receiving fertility treatment after methotrexate for ectopic pregnancy: a systematic review and meta-analysis. Hum Reprod. 2014:29:1949-56. 25056087. https://doi.org/10.1093/humrep/deu174.

14. Boots CE, Hill MJ, Feinberg EC, Lathi Ruth B, Fowler Susan A, Jungheim ES. Methotrexate does not affect ovarian reserve or subsequent assisted reproductive technology outcomes. J Assist Reprod Genet. 2016;33:647-56 PMID:26943917. PMCID:PMC4870444. https://doi.org/10.1007/s10815-0160683-7.

15. Fernandez H, Capmas P, Lucot JP, Resch B, Panel P, Bouyer J, et al. GROG fertility after ectopic pregnancy: the DEMETER randomized trial. Hum
Reprod. 2013;28:1247-53. PMID:23482340. https://doi.org/10.1093/humrep/ det037.

16. Hsu JY, Chen L, Gumer AR, Tergas Al, Hou JY, Burke WM, et al. Disparities in the Management of Ectopic Pregnancy. Am J Obstet Gynecol. 2017;217(1): 49.e1-49.e10. PMID:28288792. PMCID:PMC5484775. https://doi.org/10.1016/j. ajog.2017.03.001.

17. Cirik DA, Kinay T, Keskin U, Ozden E, Altay M, Gelisen O. Success rates of single-dose methotrexate and additional dose requirements among women with first and previous ectopic pregnancies. Int J Gynecol Obstet. 2016;133: 49-52. PMID:26873120. https://doi.org/10.1016/j.ijgo.2015.08.017.

18. Kirk E, Bourne T. The nonsurgical management of ectopic pregnancy. Curr Opin Obstet Gynecol. 2006;18(6):587-93. PMID:17099327. https://doi.org/10. 1097/GCO.0b013e3280105886.

19. Lipscomb GH, McCord ML, Stovall TG, Huff G, Portera SG, Ling FW. Predictors of success of methotrexate treatment in women with tubal ectopic pregnancies. N Engl J Med. 1999;341(26):1974-8. PMID:10607814. https://doi.org/10.1056/NEJM199912233412604.

20. Agostini A, Blanc K, Ronda I, Romain F, Capelle M, Blanc B. Prognostic value of human chorionic gonadotropin changes after methotrexate injection for ectopic pregnancy. Fertil Steril. 2007;88:504-6. PMID:17418833. https://doi. org/10.1016/j.fertnstert.2006.11.138.

21. Levin G, Dior U, Shushan A, Gilad R, Benshushan A, Rottenstreich A. Early prediction of the success of methotrexate treatment success by 24-hour pretreatment increment in HCG and day 1-4 change in HCG. Reprod BioMed Online. 2019;39(1):149-54. PMID:31029556. https://doi.org/10.1016/j. rbmo.2019.02.005.

22. Girija S, Manjunatha AP, Salahudina A, Jeyaseelan L, Gowri V, Abu-Heija A, et al. Role of day 4 HCG as an early predictor of success after methotrexate therapy for ectopic pregnancies. Eur J Obstet Gynecol Reprod Biol. 2017; 215:230-3. PMID:28683376. https://doi.org/10.1016/j.ejogrb.2017.06.020.

23. Wong L, Fung LWY, Cheung CW, Lao $\Pi$. Trends in serum human chorionic gonadotropin levels $0-4$ days after methotrexate administration for predicting tubal ectopic pregnancy treatment success. Int J Gynecol Obstet. 2018;141:245-9. PMID:29214643. https://doi.org/10.1002/ijgo.12419.

\section{Publisher's Note}

Springer Nature remains neutral with regard to jurisdictional claims in published maps and institutional affiliations.

Ready to submit your research? Choose BMC and benefit from:

- fast, convenient online submission

- thorough peer review by experienced researchers in your field

- rapid publication on acceptance

- support for research data, including large and complex data types

- gold Open Access which fosters wider collaboration and increased citations

- maximum visibility for your research: over $100 \mathrm{M}$ website views per year

At $\mathrm{BMC}$, research is always in progress.

Learn more biomedcentral.com/submissions 